\title{
Artist Mobility and the Baltic Cities: Revealing a Transnational Art World
}

\author{
EMMA DUESTER, Goldsmiths, University of London
}

\begin{abstract}
Mobility is an important part of the everyday life and practice of artists. Many artists take part in short-term mobility in order to gain inspiration, form partnerships and contacts, and create networks and/or collaborations. Some of these pathways created through mobilities are well-established while other transnational connections have only recently been formed as artists connect to new, emerging art centres. With each new connection usually linking up yet another city, and with every artist presenting a different set of connections and trajectories, the artistic 'transnation' (Yeoh and Willis $2004,1)$ is constantly developing.
\end{abstract}

This article describes how this type of short-term, multi-directional mobility not only creates connections, forms collaborations, and helps to establish transnational communities, but is also vital in helping liminal cities to become part of the so-called global art world. More importantly, these artists' base remains in the Baltic cities - Vilnius, Riga, and Tallinn - as they are moving only temporarily. This mobile population, in turn, enables the Baltic cities to become a hub of connections or 'relational spaces'. This article argues that such forging of 'routes' via mobility rather than planting permanent 'roots' (Clifford 1997, 1) in migration has helped the network of Baltic cities to form a transnational region and become part of the global art world.

\section{KEYWORDS}

Mobility, the art world, the Baltic States, the city, transnationalism.

\section{A Mobile Art World}

New social and political geographies are plotted every day through human mobility, changing the nature of space and altering the social relations between people, communities, cities and cultures. These new geographies - or trajectories - are created through communications, collaborations and in short-term movement. The art world takes part in fluid mobility and it is, and has been throughout history, a constantly moving and collaborative community. These types of mobility have, in turn, formed a globally connected space of transnational and intercultural communication, collaboration, and interactions between artists, galleries, and art institutions across large geographic distances.

Taking the idea of artist mobility and the ramifications it has on the concept of migration as its focus, this article explores how and why the artist community takes the part in short-term, multidirectional mobility and its effects on the 'home' cities of Vilnius, Riga and Tallinn. It brings together issues to do with the global art world, migration, and the city. Drawing on original 
interviews with artists and curators, it will show how important mobility is for these artists in terms of their collaborations, communications and what mobility ultimately means to them. The purpose of this study is to show how this type of mobility can challenge and complicate the current understanding of migration - which is usually conceived (by, for example, Wallace and Palyanitsya 1995; Hesse 2000; and Favell 2008) as one-way, permanent, for economic purposes, and as going from East to West. So the main question here is: how can artist mobility challenge or complicate current understandings of migration? This question will be explored through two sub-questions: why do artists take part in short-term, multi-directional mobility; and how are these artists part of and helping to develop a transnational art community?

I will argue that there is a particular type of 'artist mobility' which is short-term and multidirectional. This 'artist mobility' helps to challenge or complicate those permanent, uni-directional and Westwards notions of migration. This study works against assertions made in migration literature that looks at the idea of, for instance, the rising trend of East-West migration. Adrian Favell states that 'borders are coming down, and a new East-West migration system is being established on the continent' $(2008,702)$. Similarly, Claire Wallace and Andrii Palyanitsya state that 'the fall of the Berlin Wall led to fears of an influx of migrants from Eastern Europe. So far this "flood" has not arrived, but new patterns of migration from East to West are emerging' (1995: 89). Open borders that are present across Europe, in fact, do not only mean that migration works permanently from East to West - it can also mean that circular and short-term migration is possible.

This study is therefore especially important for developing understanding on the types of migration out of and around Europe, as it shows a positive type of movement rather than one that is negative as is usually the case, with a lot of commentary on unskilled workers permanently migrating for economic reasons to Western Europe (see Zimmerman 1995; Wallace 2002; and Mansoor and Quillin 2006). By contrast, this study explores a positive and creative movement undertaken by 'cultural migrants', rather than 'economic migrants', who use mobility in order to experience new life and cultures, gain new inspiration, make collaborations/projects with new people, and extend their network.

A lot of these artists are using space and mobility strategically; they operate across and in different spaces at once as well as working on different collaborations and exhibitions simultaneously. Some artists take on this lifestyle in order to maximise not only their income but also (and perhaps more importantly) to develop their long-term international career. They are subsequently becoming globally connected individuals. Thus, this community operates through relational spaces across multiple cities which are located in different countries. This shows how social processes help to produce transnational spaces - as David Harvey puts it, 'shap[ing] the land through their activities' $(1996,310)$. Thus, artists are not only cultural producers nor simply a community of practice but are also social and spatial producers, creating the 'shape' and 'position' of spaces through their practice as well as through their mobility and the new connections that this creates.

The transnationalism of Baltic artists also has an impact on the 'home' city. This is because the connections and collaborations artists make with art institutions abroad through mobility means that touring exhibitions and 'foreign' artwork is shown in the Baltic cities. Also, the artists who travel bring new influences to the exhibitions they do at 'home'. This increases the 'profile' of the Baltic cities, draws these cities into the global art world, and means that links are not only one-way and that mobility is not only bringing artists from these cities but also bringing transnational influences 
in. Admittedly, it does seem that there are a lot more flows going out than there are coming in; but this is gradually changing with more internationally-renowned artists and curators, new policies within visual arts and international relations, and an increasingly better economic situation in the Baltic States.

With artist mobility, the Baltic cities are witnessing not necessarily a 'loss' of talent with artists moving out of the cities but, instead, a circulation of talent - with an exchange of ideas across the transnational art community. Thus, the Baltic cities are not losing anything from this type of movement but, rather, gaining from it. And this is in stark contrast to migration which denotes a permanent movement, suggesting that the 'home' city feels a loss of people, 'talent', and a decline in the economy.

These artist communities on the so-called liminal edge of Europe in Vilnius, Riga and Tallinn are, in fact, transcending cultural and artistic boundaries and are more relational and connected today. Thus, such places are only liminal in terms of their physical location rather than in their connectedness. Also important is that in art fairs, biennials, and collaborative exhibitions, these liminal cities are increasingly being positioned alongside 'global cities' (Sassen 2001, 1) such as London and Berlin, as well as being publicised and consumed in these global cities. So it can be argued that these so-called liminal cities are in fact 'relational spaces'. One thing is for sure: the Baltic art worlds need to be seen in terms of their expanding and increasingly relational geographies and their international presence.

\section{Migration, or is it Mobility? Changing the Spatiality and Temporarily Across Europe}

This section details the important distinction to be made between migration and mobility. By looking at the literature on migration, it will show a gap for the idea of 'mobility'. It will explore how mobility is forming new spaces that span across borders and cultures. It will look at areas in the literature on the 'transnational social space' as well as social and spatial relations between cities. First, the differentiation between the 'nation-state' and the city is outlined in order to show on what level artists are operating across space.

In an increasingly connected and globalised world, it is becoming more necessary to move away from discourse centred around the 'nation-state'. Instead, the nation-state itself is becoming decentred as a result of the many diasporic populations living across the globe, who are planting roots away from the conventional 'homeland'. The nation-state therefore becomes an 'imagined community' (Anderson 1983, 1) of people dispersed across multiple borders, and within its boundary is a mixture of cultures. Furthermore, borders are breaking down and continuously being crossed - so the nation-state (as a term) is increasingly decreasing in importance. Especially in the everyday lives of artists, transnationalism is today more commonplace as they operate within networks and collaborative projects that include members from multiple countries and they move back and forth from their 'homeland'. Some artists are even hyper-mobile, whereby they hop from one city to another without returning to 'home' for an extended period of time. As Estonian artist Kris Lemsalu put it, 'I just came from Berlin back to Vienna, Sunday to Berlin, Tuesday to Miami, Next Sunday to New York for a month, then Berlin, Estonia, London, Berlin, Vienna' (participant observation, 28 November 2013). Taking part in such mobility means that such artists have a different outlook on ideas of 'home' and 'roots'. Artists seem to live in and through travel, going to 
one place for a few weeks to put on an exhibition and going to another place to collaborate with other artists for a few weeks. They are seemingly almost dwelling in or finding roots in travel finding 'roots' in their 'routes' (Clifford 1997, 1).

For most artists, cities are where they decide to locate themselves and work; they also move between cities when travelling through different countries. A lot of artists move out of the city but at the same time come back and forth, rather than simply leaving the country permanently as in migration. It is the city to and from which artists' connections are made as well as where their transnational spaces are formed. For example, a transnational space was created by Estonian artist Laura Põld who collaborated with Latvian artist Sigita Daugule towards a joint exhibition entitled Laura Pôld / Sigita Daugule at Gallery Ulrike Hrobsky in Vienna from $13^{\text {th }}$ September to $19^{\text {th }}$ October 2013. Saskia Sassen looks at 'the mobility and liquidity of capital' and 'global markets' that serve to link up cities, claiming that these processes happen on 'sub-national entities', such as between cities. She says due to the globalisation of economic activity, analysis requires a new 'conceptual architecture', and cities (especially the global city) are important in this new architecture $(2005,27)$. This can also be said to be the case with the mobility of people and objects as well as connections between people, which happens between cities. As with Sigita and Laura, they created a transnational space linking up Vienna with Riga and Tallinn. Thus, migration within the art world needs to be seen as going from one city to another, rather than from one country or 'nation-state' to another.

Migration is usually seen as permanent, going from East to West, and taking place for economic reasons. As a way of presenting a new and more complex understanding of migration, however, I want to hold it up against the idea of 'mobility'. The circular and multi-directionality of mobility contrasts with migration that is assumed in most of the literature as one-way and permanent (see figure 1). Furthermore, migration is usually seen as only a physical movement, but mobility can include different types of movement, including the physical movement of people or objects and the virtual movement of communications. Within the art world, there is a mobility of artists, artwork, money, and grants/scholarships as well as a mobility within collaborations and communications between members of the art world.

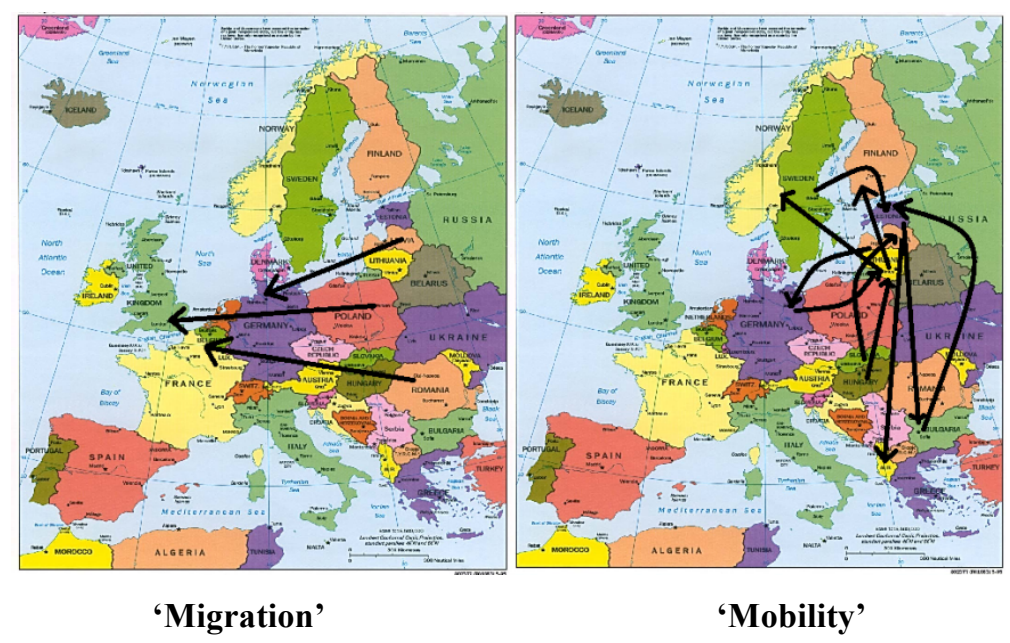

Figure 1 
In previous research on migration (Hesse 2000; Agnew 2005), a lot of the theory adopts a negative view of migrants, stating that mixing cultures creates 'transruptions' (Hesse 2000,1) and that diasporas are just concerned with 'memory: a search for home' (Agnew 2005, 1). This area of research is well-developed. Thus, this study directly intervenes in this literature by proposing a migration that is creative, short-term, multidirectional, and a positive movement. It moves away from looking at migration as negative and binary. Therefore, 'mobility' is a more apt term for this type of movement. That is to say that there is room for migration to have a more open meaning, one which can also be inclusive of movement, communication, and collaboration.

Migration literature (such as Dodani and LaPorte 2005; and Chappell and Glennie 2010) generally argues that one of the main negatives of movement, and especially permanent movement, is the 'loss' felt in the home country. For example, such losses could be 'brain drain', economic downturn, or population decline. But this is far from the whole story; rather, the new generation of young artists have found a way to live through travel but to also keep their main home in the Baltic States, by regularly returning to their home city. As a Professor at the Estonian Academy of Arts Mart Kalm says 'artists are not permanently migrating. Artists are not expected to stay in one place. There's not a brain drain in the art world. There's a brain drain of doctors who go to Finland and America. Not in the art world because they come back' (personal interview, $7^{\text {th }}$ June 2013).

Lastly, another problem with previous scholarship is that a lot of studies of migration patterns discuss one home country and one host country and the bilateral communications that are made between these two locations (for example, Chaney 1979; Basch et al. 1994; and Gupta 2007). But is this really transnational? Aren't the relations between multiple countries and reciprocal migration more in keeping with the idea of transnationalism? Transnationalism, it can be argued, is not only the breaking down and then transcending of borders but actually the connecting up of multiple places across these borders. Today, both migrants and mobile practitioners do not necessarily only form relations with the home or host society; instead, they now have ties in multiple countries through their work and everyday lives.

\section{Travel and Transition: James Clifford's Conception of Roots and Routes in Travel}

As I have touched on above, alongside theories surrounding migration and mobility, it is productive to utilise James Clifford's concept of the traveller whose 'roots always precede routes' $(1997,3)$. This could be thought of in terms of a community operating initially from the local - where their roots are placed - but extending out to the global, through connections, communications, and collaborations. It is the production of these connections that gives artists the impetus to take part in short-term mobilities - their routes. Estonian artist Kristi Kongi says that

being an artist is moving work, a moving job. There has to be a place at home though. I like moving around. I like living in strange places, researching places, and I like being a stranger somewhere. Go to one place, be there for one month, and then come back. (personal interview, $1^{\text {st }}$ August 2013)

Thus, while 'roots' are being planted in physical migration, 'routes' are found in this new conception of mobility. 
However, each artist's experience is different. As a result, they have different ways of locating themselves in their travels, and also different ways of connecting across cities. Some find 'roots' in their 'routes' across Europe and further afield, but others keep their 'roots' firmly placed in their Baltic 'home' cities. There can also be a differentiation made between artists who migrate permanently (fixed migration), artists who migrate temporarily or on artist residencies (short-term mobility), and artists who hop from one city to another or just communicate or collaborate remotely (ultra- or trans-mobility). These different circumstances dictate the type of 'roots' or 'routes' artists form. Thus, in permanent migration artists usually create new roots in the host country, while in short-term mobility artists carve out routes.

These routes are creative because there is an exchange of ideas but also the creation of new ideas through cross-cultural collaboration. Clifford questions, 'what stays the same when you travel? What is brought from a prior place? And how is it both maintained and transformed by the new environment?' $(1997,44)$. When artists travel they take aspects from the 'home' culture but use the new environment to re-invigorate these ideas and understandings. So both cultures are brought together to create something new in their art. When asked how travel affected her artwork, Kristi Kongi said that 'I take bits from everywhere. I'm always taking new things in' (personal interview, $1^{\text {st }}$ August 2013). Mobility has an affect on artwork as well as space. Clifford also says that space is constantly being reconfigured through travel, the effects of this he calls a 'transculturation'; the connections and merging of cultures in turn provide a 'zone of exchange', forming paths between cities, both central and peripheral (ibid.).

\section{A Mobile Community: The Trends, Reasons, and Restrictions of this Type of Movement}

This section will go into more detail about the trends, reasons, and restrictions characterising artists' mobility. There are several reasons why artists are mobile. These come under the broad headings of mental enhancement, networking, study purposes and economic motivation. Thus, there are benefits of mobility that are both psychological as well as career-related. Also, even with the presence of the internet many artists still believe that mobility is important to be part of the international circuit, necessary to 'get recognised', and is vital in order to sell artworks. Furthermore, if artists stay in one place and remain in their home city they are less likely to experience other perspectives and less likely to come across other ways of thinking.

Therefore, for artists, mobility can provide a kind of freedom: a way to experience or be immersed in environments with new ideas, other ways of thinking, or new styles. This mobility opens artists' minds and allows them to gain a broader perspective on their life and work. A Project Manager at KIM? Contemporary Art Centre says that mobility 'opens your mind' (KIM? Contemporary Art Centre, personal interview, 23rd April 2013) and, according to the Director of NOASS in Riga, artists gain a 'broader perspective' (NOASS, personal interview, 24th April 2013) from this. Also, a lecturer from the Estonian Academy of Arts says that through travel you can 'free yourself' (personal interview, 5th June 2013). One aspect of this is that mobility provides a distance from 'home' where all is familiar and normal; so when artists move away they can see more clearly what is happening at home, as well as differences between cities and its culture. This distance can give artists clarity. Hence, it is invaluable not only for the soul and for them personally but for progressing their career. 
There are also psychological benefits that mobility can provide. Mobility can act as a developmental process for artists, akin to that of learning. Astrida Rinke, the owner of Gallery Alma in Riga, says it is 'like learning, you understand your personality' (personal interview, 24th April 2013). Artists can learn about art practices and styles elsewhere but also learn about themselves in terms of their personality and the way they produce art, think about art, and their style - because they can compare it to others and see it afresh in a new environment. Another factor is the benefit of being a 'stranger' in a foreign country as well as being confronted with 'strange' surroundings; this type of environment generates the inspiration to produce art. Through putting themselves in these 'strange' environments, which are partly challenging and risky and partly exciting, artists' confidence and self-esteem is boosted and this helps them grow as a person as well as an artist. A lecturer from the Estonian Academy of Arts says that 'physical space gives you mental space. It shows you what is distinct about home' (personal interview, 5th June 2013). Thus, artists learn not only about other cultures but, in turn, learn about themselves and their own culture too.

These processes, changes, and adaptations to their career and mental state will naturally be reflected in their artwork. As Estonian artist Tiina Soot confirms, 'this experience affects my work a lot' (personal interview, $27^{\text {th }}$ August 2013) and, similarly, Latvian artist Dita Luce says that her 'art is very much influenced by travel. Travel is inspiring in general, it is a way to gather impressions and my impressions appear in my art' (personal interview, $10^{\text {th }}$ August 2013). Thus, mobility changes these artists and this change can also be seen in their artwork. Most artists' primary reason for being mobile, therefore, is not economic but rather cultural, psychological, and/or professional.

A lot of artists have also been abroad to several places, but not necessarily for the purposes of art per se. At the beginning of their career, artists may go abroad to gain inspiration and understand other art styles (as was mentioned above). However, they do not like being a 'typical tourist', but rather, every trip has to have a purpose, centred around looking for inspiration and new influences. For example, Lithuanian artist Vytautas Virzbickas says 'I went to get experience, to see what they are doing there' (personal interview, $28^{\text {th }}$ August 2013). Artists are not economic migrants but 'cultural migrants' wanting to experience a new culture, new life, and new inspiration. As Lithuanian artist Deimantas Narkevicius says, "we are cultural nomads. Not economic migrants, more cultural migrants' (personal interview, $27^{\text {th }}$ August 2013). Sometimes artists use mobility for attending exhibitions or projects, but other artists travel for experience and life-enhancing journeys that are not necessarily for work. However, both of these motivations for travel will change them as a person, their knowledge of the world, and their outlook on the world - and this will be reflected in their artwork.

One of the main trends or distinctive aspects of 'artist mobility' is that this mobility is not 'ordered', in that it does not only work towards key global cities like London or Berlin. In fact, each artist has their own trajectory and, thus, their own transnational community or space. For instance, Estonian artist when interviewed Merike Estna had travelled between London, Tallinn, Berlin, New York, Istanbul, and Mumbai over the last six months. By contrast, Lithuanian artist Zygimantas Augustinas had developed ties over the past three years with Vilnius (Lithuania), Arad (Romania), Tuzla (Bosnia and Herzegovina), Viborg (Denmark), Valladolid (Spain), Kaliningrad (Russia), Namur (Belgium), and Venice. Such multi-directional and idiosyncratic 'artist mobilities', shows a marked distinction from the current understanding of migration. They are based on the personal connections of artists and so happen in a 'sporadic' way. There seems to be something inside artists that means they enjoy being mobile and even live through this kind of short-term mobility, or 
perhaps it is just accepted today that it is part of the job.

\section{Mobility and the Production of a 'Transnational Social Space'}

This section will discuss the effects of this mobility on 'space' and the city. It will look at how mobility can help to produce a 'transnational social space' across cities. Previous theory does not make this direct connection but does state that a 'transnational social space' is present amongst migrant communities, through communications that are made between family and friends of the same nationality who are in different locations. This set of theorists (Faist 2000; Castles and Miller 2009; Yeoh and Willis 2004) look at how migrants create communities, networks and events that cut across space. This work helps to develop the meaning of transnationalism. However, the idea of transnationalism can be progressed further still, as transnationalism does not have to only mean the ties between migrants' 'home' and 'host' societies, but between many cultures and across multiple spaces, whether the same nationality or not. It is important to look at this here because, through mobility, a transnational social space or community is created, which is, moreover, distinct to each artist.

It is important to look at mobility within Europe, in particular, because, as Zhanna Zaionchkovskaya argues, 'migration patterns are useful indicators of social change" $(1996,15)$. This is important as the mobility of artists changes the nature of space and social relations. This can also be seen through the transition happening within the Baltic cities, and here Zaionchkovskaya argues that this transition in society is indicated through patterns of migration (ibid.). Zaionchkovskaya looks at the change in migration patterns and the simultaneous change in society during the collapse of the Soviet Union (1990-1994), but her argument is still relevant for mobility today. The Baltic city can include a transnational space (or multiple transnational spaces) that extends outwards from the city to other parts of Europe as well as further afield - and this is dependent on the connections artists have across different cities. Zygimantas, who is shown above to have a multi-urban and 'sporadic' set of connections has had his work represented by Gallery NB in Viborg since 2011, while a gallery in Arad produced a show with his work, and another in Tuzla invited him to the international portrait biennial Interbifep in 2011 and 2013. Earlier in 2013 he was part of the CreArt project 'More Real than Real' in Valladolid, the 'Century Portrait' at Kaliningrad Art Gallery. In 2012 he was part of the 'Contemporary Drawing Bienniale' in Namur, and in 2011 he was part of the 'Behind the White Curtain', a project by Darius Miksys, at the Venice Biennial.

Different generations of migration - both past and present - are described by Thomas Faist (2000, 11) as 'phases', but not in terms of periods through history but in terms of the different types of migration. He sees the first phase as the push-pull nature of migration and the second phase as labour migration and refugee flows that took place between categorically 'emigration' and 'immigration' nations. The third stage is when migration takes place in transnational social spaces, 'connecting both worlds' (ibid., 12) of 'home' and 'host' country, and is more to do with moving from one city to another.

The current 'phase' in migration, or mobility, is to do with migrants' transnational networks and space they create through their multiple connections. Baltic artists create a relational space across cities within Europe which, thus, not only follow predictable routes of one sending (home) and one receiving (host) country. Zygimantas, for example, reports that he goes East and West in his 
mobility and to typically 'sending' as well as 'receiving' cities. This relational space is created in the third stage of migration, as Faist says, which links multiple places and people. The emergence of contemporary global geographies due to today's multi-directional mobilities has aided the formation of links and relational spaces across multiple places; these relations were present in history, but not with the same intensity and multi-directionality, and not in such large numbers.

Artist networks are a good example of a relational space, as everybody within the networks acquires a relational space that connects to multiple locations in the region 'within a web of ties' (Faist 2000, 2). This means they create a transnational social space that depends on the collaboration and interaction of people across multiple different cities. In Zygimantas' case, he is in regular contact with gallerists and curators in Arad, Tuzla and Viborg. Also, Merike lives in London but travels a lot and is represented internationally in art fairs and shows by the Temnikova and Kasela Gallery in Tallinn, so is in regular contact with them. This shows a distinct development in migration in recent times: these artists do not simply migrate, but instead move for a short period and then interact and connect with new people and places, forming new paths of connection.

This is what Faist conceives as the 'transnational social space', a relational space with continual (re)connection between migrants within a community $(2000,2)$. As is shown with the examples of Zygimantas and Merike, this art community connects across large geographic distances. The literature on migration and transnationalism discusses migrants' networks and connections across space between people of the same culture - but their interaction with different cultures, nonmigrants, and multiple countries is hardly mentioned. Furthermore, due to the links artists make in mobility, when they come home these links are still ongoing, as they have made long-term partnerships. So the Baltic cities become a hub of connections outwards and inwards. The city as a physical place includes many spaces that extend out across Europe to many different cities.

\section{The Impact of Artist Mobility on the Baltic City}

The spaces artists create through mobility and connections has had an effect on the cities of Vilnius, Riga and Tallinn. They are no longer cut off from the global art world and are, instead, emerging transnational art communities. 'It's not so separate anymore' as Merike says (personal interview, 13/12/2013). It is important to note that, as well as the blind-spots identified above, most of the literature on migration also only talks very broadly of 'homeland' or the 'home country'. By focusing my analysis on the city, and how the city as a space is changing with artist mobility, it becomes clear not only that artworks and artists are affected by mobility, but that there are also effects on the Baltic cities themselves. These include the contemporary vis-à-vis traditional art world, the pulls between both nationalisation and internationalisation, and new types of art spaces that are opening up across the city.

Not only a 'space of flows' nor a 'space of localities' as Manuel Castells (1989) and Zygmunt Bauman (2011) have previously suggested, but, the Baltic cities are now a 'space of relations'. These cities are now places that includes many spaces that reach beyond their geographical perimeters. It is important to look at the effects on the city within the Baltic States because just over two decades ago neither communications nor people were allowed to leave the Soviet Union, and yet today these cities have become 'post-post-Soviet spaces' of mobility, communication, and collaboration - no longer in the shadow of the closed and bordered world of the Soviet period. The artists are moving out temporarily, but this in turn forms connections, whereby collaborations and 
projects come back into the Baltic cities - in the form of partnerships that are forged between cities. An example of this is the Baltic states' links to Scandinavian countries - which have now reestablished links with Estonia. Both a curator working in Vilnius and a PhD director at the Estonian Academy of Art mention this connection: Aurime Aleksandavicuite says that 'in this region Nordic funding is quite substantial' (personal interview, $16^{\text {th }}$ December 2013) and Mart Kalm says that 'Nordic countries have the provision for money for the Baltics. So we get a lot of collaborations from this. But connections are both ways today. We can finance international projects too' (personal interview, $7^{\text {th }}$ June 2013).

Rather than looking at the linkages binding a city to real/virtual places around the globe as Saskia Sassen (2001) has done, it is vital also to explore the globe-spanning effect that is taking place within cities and what effect these linkages are having on the Baltic city. For this study, what is required is an assessment of mobilities outwards but also the effects of these movements on the 'home' city. Thus, due to their mobilities the Baltic city can include many spaces with linkages coming into the city from elsewhere as and when artists return from their travels. This then forges links with other cities across Europe, creating an extended space outwards from the Baltic city. When referring to 'transnational space', therefore, this does not necessarily mean the links across countries, which Sassen (2001) has demonstrated, but instead also the idea or concept that one place (for instance, the city) can include many 'spaces'. For example, for Zygimantas, his base is in Vilnius but he operates in spaces that link to Viborg, Tuzla, and Arad. In turn, this means Vilnius is part of multiple transnational spaces.

As a result, the Baltic art community has formed a de-centralised and even fragmented 'art nation' across the European region. Nevertheless, even though they do not occupy the same space, territory, or state (necessarily), they do still inhabit the same 'art space' and art community. This is what Yeoh and Willis call a 'transnation', whereby the nation is de-coupled from the state $(2004,1)$. As they argue, once people start to recognise that the nation need not be seen as 'within one territory', then we can see how these transnational communities work and this brings into view a world with a new kind of 'human organisation' (ibid., 12). This art world, then, is a transnational community that is made up of multiple connected local settings spread across different cities. Yeoh and Willis believe that the way forward is to decouple the nation from the state, and then a space is created whereby 'peoples can form nations without occupying the same territory' (ibid., 3). This shows one way in which art worlds can be theorised, as a 'nation' of their own, spread across many cities.

In fact, the Baltic cities provide a lot of opportunities for artists and this is perhaps why a lot of artists do not move out permanently. As there are positives to the so-called peripheral or emerging art world: there is less bureaucracy surrounding the work, it is cheaper to produce art and to rent studios, and there is more freedom to exhibit in a variety of spaces and to change these spaces for the purposes of the artists' exhibition. As Latvian artist Sigita Daugule says, 'it is relaxing here. I like staying here. There is more bureaucracy and taxes in Vienna and Western Europe' (personal Interview, $12^{\text {th }}$ October 2013). In practical terms, for example, if an artist wants to do an exhibition in a church or factory, this can be realised efficiently and with comparatively little expense. Also, everyone has an equal opportunity to get their work exhibited, even students. Thus, this position might be advantageous as by using short-term mobility artists gain the best of both environments. For instance, Sigita travels in order to install exhibitions and to continue to form her network, but spends a lot of time in Riga as she lets several galleries who represent her work to sell and show her art internationally. As she puts it, 'I have two galleries in Vienna, one in Salzburg, one gallery in Germany near Koblenz, two galleries in Riga, one art investment company in London [...] they are 


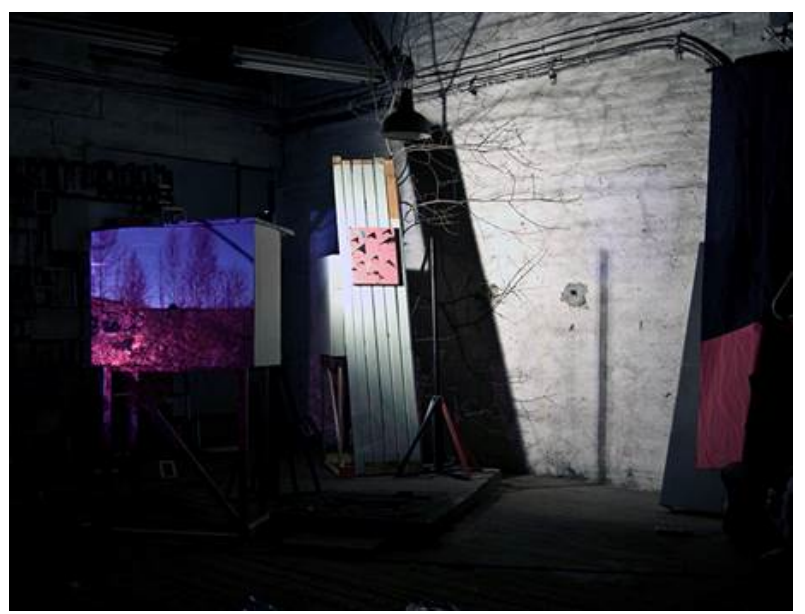

Figure 2: 'Attempts to Stage a Landscape’, Laura Põld, Kunstihoone, Talinn, $31^{\text {st }}$ May - $23^{\text {rd }}$ June $_{2013}$

my agents or representatives' (personal interview, $12^{\text {th }}$ October 2013). Furthermore, the position of these cities is still improving, with several interviewees talking of transition and 'connections that are getting better and better' (Tiina Soot, personal interview, $27^{\text {th }}$ August 2013). This is why, therefore, some artists are drawn back to the Baltic cities and artists who are mobile usually return.

Today there is a thriving contemporary art world in Vilnius, Riga and Tallinn. It encompasses mixed-media installations, which change the exhibition space and require the artist to travel with the piece to the exhibition and 'install' it. Estonian artist Laura Põld's mixed-media installation entitled 'Attempts to Stage a Landscape', exhibited at Kunstihoonein in Talinn throughout June 2013, used a mixture of painting, video, collage and found materials (see figure 2). This type of art is, today, overshadowing the traditional art world, which now only exists in the form of a few commercial art shops with paintings of typically 'Baltic' scenes. This shows a dramatic change in the understanding of visual art in the Baltic States. This could be the next generation of art from the Baltic states, which is no longer predominately concerned with the 'post-Soviet' condition, of nostalgia and darkness, or of the 'Baltic' condition per se but rather with an era of openness and connectedness as well as interdisciplinary and mixed-media approaches. The artwork is no longer geographically specific, but is open to current and new ideas happening in the global art world. This type of art is exhibited in well-renowned art spaces such as the Contemporary Art Centre in Vilnius, Riga Art Space in Riga, and Kunstihoone.

Mobility also changes ideas to do with the notion of national vis-a-vis international in artworks, artists' minds, and within the Baltic city. Even though the national remains important as it constitutes the artist's roots, it is framed in a global context once an artist has travelled. Laura said that once she had travelled and spent time in Vienna she realised the differences between the two cultures, subsequently increasing her understanding of her own culture and how to portray this in her artwork (personal interview, $7^{\text {th }}$ June 2013). This means that even if her work is depicting the 'local' she is doing it in such a way that shows it in a global context and whereby she is part of a global art world. So, as such, mobility allows artists a context and an ability to position their own culture against others. 
There is also a transition in the Baltic city in terms of a change in which art spaces are located across the city as well as the renovation of disused buildings through artist-led or funded art projects. Artists and curators are opening up their own art spaces in their 'home' city, and they are doing this in new areas of the city away from the centre. Thus, art spaces are gradually moving further away from the city centre and deeper into the so-called 'sleeping districts'. This means contemporary art is more visible all across the cities, and it is (literally) changing the landscape of the city. This highlights how there is increasing support for contemporary art from the Ministry of Culture and that there is more funding for galleries to show this type of art.

All of these factors, together, are changing the landscape or geography of the Baltic cities. The physical geography of these cities is being changed by the opening of new art spaces and the space of the city is being moulded and extended outwards by mobility and the transnational art community creating a transnationally-oriented urban space. As these artists are helping to do this within a community of practice, I argue that what is happening with this current generation of artists is the creation of a 'relational space'. By taking their art to multiple locations and forming many collaborations with different cities, the extended or transnational space of the Baltic cities is ever changing and itself is a mobile, changing and adapting landscape.

\section{Conclusion}

This article has looked at the mobility of artists and its effects on the Baltic cities. It has considerd issues to do with mobility, migration, and transnationalism, in relation to the Baltic city. Drawing on first-hand experiences of Baltic artists, I have presented a particular type of short-term, multidirectional mobility that artists take part in, the subsequent transnationalism of the Baltic art worlds through the creation of their 'transnational social spaces', and the effects of this on the Baltic cities. This analysis was undertaken in order to show how mobility can provide a re-framing of migration. I has proven this by highlighting that there are other types of migration that need to be explored. Furthermore, I have argued that we need to account for the creative potential of these types of movement on the home cities, rather than seeing movement as just negative or as a 'loss'. This has presented a development of the existing literature by suggesting these artists no only communicate between home and host societies but partake in multiple networks and spaces of communication at the same time, linking up with multiple cities and people not necessarily of their own nationality.

Artists from the Baltic cities are developing their connections across Europe and are, subsequently, becoming part of a transnational network or community. This includes more connections across cities, connections that are reaching ever further afield and to more and more new places. The Baltic cities are no longer only connected to each other or eastern Europe, as was the case during the 1990s and 2000s. Whether it is a necessity or out of choice, it is due to the mobility of artists that the Baltic cities have become part of the global art circuit. An important factor in this transition is how open and international these societies are today. Instead, they have entered a new decade, and what comes with this is difference, openness, multi-directional communications and multiple opportunities for collaboration. Baltic artists do not feel outside the global art world and thus do not only stay within their country or communicate only with themselves. Instead, their ambition right from the outset of their career is to become international or to become global practitioners.

Thus, today with these flows going in and out of the region, the Baltic cities contain within them emerging transnational art communities. They are still in transition towards this, but what is visible 
is the increase in connections, the opening of new art spaces, the use of different areas of the city and new buildings as art spaces, and change in policy towards a favourable understanding of contemporary art. Thus, in Clifford's terms, through 'routes' rather than 'roots' the art community can create a 'trans-nation' (Yeoh and Willis 2004), so they are not necessarily global cities but rather relational cities. And these relational spaces allow an environment for trans-cultural spatial relations, creative mixtures and transnational collaboration. This culminates in a new type of migration, which, as I have argued in this article, is better understood as mobility.

\section{References}

Agnew, V. (2005) Diaspora, Memory, and Identity: A Search for Home, Toronto: University of Toronto Press

Anderson, B. (1983) Imagined Communities: Reflections on the Origin and Spread of Nationalism, Verso Books: New York

Bauman, Z. (2011) Collateral Damage: Social Inequalities in a Global Age, Cambridge: Polity Press

Castells, M. (1989) The Rise of the Network Society, the Information Age: Economy, Society and Culture, Chichester: Wiley-Blackwell

Chappell, L. and Glennie A. (2010) 'Show Me the Money (and Opportunity): Why Skilled People Leave Home - and Why They Sometimes Return', Migration Policy Institute, [online], April. Accessible at http://migrationinformation.org/Feature/display.cfm?ID=779. Accessed 20 January 2014

Clifford, J (1997) Routes: Travel and Translation in the Late Twentieth Century. Cambridge: Harvard University Press

Dodani, S. and LaPorte, R. (2005) 'Brain drain from developing countries: how can brain drain be converted into wisdom gain?', Journal of the Royal Society of Medicine, 98(11), 487-91

Favell, A. (2008) 'The New Face of East-West Migration in Europe', Journal of Ethnic and Migration Studies, 34(5), 701-16

Harvey, D. (1996) Justice, Nature and the Geography of Difference, Malden: WileyBlackwell

Hesse, B. (2000) Un/settled Multiculturalisms: Diasporas, Entanglements, Transruptions, London: Zed Books

Mansoor, A. M. and Quillin, B. (2006) Migration and Remittances: Eastern Europe and the former Soviet Union, World Bank Publications: London

Sassen, S. (2001) The Global City: New York, London, Tokyo. Princeton: Princeton University Press.

--- (2005) 'The Global City: Introducing an Idea', The Brown Journal of World Affairs, 11(2), 27-43

Wallace, C. and Palyanitsya, A. (1995) 'East West Migration and the Czech Republic', Journal of Public Policy, 15(1), 89-109 
Yeoh, B. and Willis, K. (2004) State/Nation/Transnation: Perspectives on Transnationalism in the Asia-Pacific, London and New York: Routledge

Wallace, C. (2002) 'Opening and Closing Borders: Migration and Mobility in East-central Europe', Journal of Ethnic and Migration Studies, 28(4), 603-25

Zaionchkovskaya, Z. (1996) 'Migration Patterns in the Former Soviet Union', in J. R. Azrael and E. A. Payin (eds), Cooperation and Conflict in the Former Soviet Union: Implications for Migration, Rand Corporation, [online], pp. 15-47. Accessible at http://www.rand.org/content/dam/rand/pubs/conf_proceedings/CF130/CF130ch2.pdf. Accessed 12 October 2013

Zimmerman, K. (1995) 'Tackling the Euro Migration Problem', Journal of Economic Perspectives, (9)2, 45-62

\section{Interviews}

Aleksandavicuite, A., interview, $16^{\text {th }}$ December 2013

Daugule, S., in-depth interview, $12^{\text {th }}$ December 2013

Director of NOASS, interview, 24th April 2013

Estna, M., in-depth interview, $13^{\text {th }}$ December 2013

Kalm, M., interview, $7^{\text {th }}$ June 2013

Kongi, K., in-depth interview, $1^{\text {st }}$ August 2013

Lecturer at Estonian Academy of Arts, interview, 5th June 2013

Lemsalu, K., participant observation, $28^{\text {th }}$ November 2013

Luce, D., in-depth interview, $10^{\text {th }}$ August 2013

Narkevicius, D., in-depth interview, $27^{\text {th }}$ August 2013

Põld, L., in-depth interview, $7^{\text {th }}$ June 2013

Project Manager at KIM?, interview, 23rd April 2013

Rinke, A., interview, 24th April 2013

Soot, T., in-depth interview, $27^{\text {th }}$ August 2013

Virzbickas, V., in-depth interview, $28^{\text {th }}$ August 2013 